\title{
A REFORMA DO ENSINO DE LÍNGUA INGLESA NO BRASIL NO CONTEXTO \\ DA REESTRUTURAÇÃO PRODUTIVA*
}

Magali Saddi Duarte**

\section{RESUMO}

Este artigo é parte da dissertação $O$ ensino de inglês para o nível médio na reforma educacional brasileira: a noção de competência comunicativa no livrotexto e tenta apreender a relação da reforma educacional brasileira do ensino de inglês no nível médio, com base nos referenciais econômicos e políticos que se desenvolveram na década de 1990, sob a ótica das competências. Apresenta os princípios básicos da reforma no que refere ao ensino de inglês para o nível médio apoiando-se em documentos produzidos pelo governo federal e conclui que, de fato, existe uma relação entre as produções teóricas sobre aquisição de língua estrangeira, políticas econômicas e educacionais.

Palavras-chave: reforma educacional brasileira; parâmetros curriculares nacionais; competências; língua estrangeira.

\section{INTRODUÇÃO}

No âmbito da Lei de Diretrizes e Bases da Educação Nacional (LDB), n. 9.394, de dezembro de 1996, a disciplina de língua estrangeira (LE) volta a ocupar lugar no currículo nacional no momento em que a mundialização da economia, a reestruturação produtiva, denominada acumulação flexível, e as novas tecnologias destacam a educação e o domínio da língua inglesa em nível internacional.

\footnotetext{
* Artigo recebido em 17/2/2007 e aprovado em 30/5/2007.

** Mestre em Educação e professora no Centro de Estudos e Pesquisa Aplicada à Educação (CEPAE/ UFG).
} 
No processo de globalização, é inegável que o domínio do idioma inglês, língua franca, torna-se imprescindível. No caso do Brasil, onde o português é a língua falada, e o país não faz fronteiras com países de língua inglesa, inicia-se uma discussão na lingüística aplicada sobre a pertinência do domínio das habilidades - falar, compreender o idioma falado, ler e escrever - no nível fundamental. Alguns teóricos defendem que, pela inexistência das condições ideais de ensino - tais como falta de professor com formação lingüística, número reduzido de horas-aula, poucos recursos didáticos e falta de infra-estrutura -, o professor opte por dar ênfase à leitura. Essa orientação presente nos parâmetros curriculares nacionais $(\mathrm{PCN})$ tem causado controvérsia no meio acadêmico. Ora, para os alunos da rede pública, a escola de níveis fundamental e médio é talvez a única possibilidade de eles adquirirem o idioma que lhes é estrangeiro. Sendo assim, seria razoável da parte da administração pública pensar o ensino global da língua, sinalizando para a superação dos problemas.

No nível médio, complementando a LDB n. 9.394/96, os PCN não tratam desta ou daquela habilidade a ser desenvolvida. Fundamentados pelas diretrizes curriculares nacionais, adotam um discurso de formação de indivíduos mais autônomos, solidários, competentes e responsáveis. Assim, difunde-se a idéia de uma formação que seja baseada no desenvolvimento das competências, que propicie ao aprendiz a possibilidade de entender a realidade na qual está inserido e sobre a qual pode agir.

A "noção de competência(s)" veiculada pela legislação educacional, no Brasil, propõe que o currículo seja flexível, pois a sociedade encontra-se num contexto em que as informações e a produção tecnológica são processadas de maneira muito rápida, demandando o perfil de um novo cidadão, polivalente, adaptativo e competitivo. Dessa forma, fica evidente a concepção de que educar é promover o ajustamento do aprendiz a uma determinada realidade.

\section{CONTEXTo MUNDiAL: ECONOMIA E CULTURA}

As mudanças político-econômicas e culturais ocorridas por causa da crise do sistema capitalista, iniciada na década de 1970, intensificaramse no Brasil nos anos 90. Entre elas, podemos citar a demanda de uma nova reestruturação produtiva, que afetou tanto o mundo do trabalho 
quanto as políticas sociais. Essas mudanças ocorridas em nível mundial, nos países desenvolvidos, não se refletem no processo político-econômico e cultural do Brasil de forma homogênea e simultânea. Harvey (2000), ao tratar da reestruturação produtiva, diz que, apesar de estar em andamento um novo padrão de acumulação de produção nos países desenvolvidos, em muitos lugares ele ainda não se verifica plenamente, havendo uma combinação dos modelos de acumulação taylorista-fordista e flexível.

A emergência de um novo modelo de acumulação - denominado de acumulação flexível - evidenciou o desemprego estrutural e a não generalização da industrialização pressuposta pelo padrão de regulação taylorista-fordista. Tornaram-se necessárias mudanças no interior do padrão de acumulação (Frigotto, 1998). Alguns dos motivos apontados para a geração da crise vivida são: a queda da taxa de lucro (principalmente por causa do aumento de preço da força de trabalho); o esgotamento do padrão de acumulação taylorista-fordista de produção; a hipertrofia da esfera financeira; o aumento acentuado das privatizações; e a crise do Welfare State ou do Estado do bem-estar social (ANTUNES, 2000, p. 29-30).

O processo de acumulação flexível "gera o fenômeno paradoxal de ampliação do trabalho precarizado e informal e da emergência de um trabalho revigorado, no qual o trabalhador multiqualificado, polivalente, deve exercer, na automação, funções muito mais abstratas e intelectuais, implicando cada vez menos trabalho manual e cada vez mais a manipulação simbólica" (Deluiz, 2002, p. 2).

Reinaugura-se um novo patamar de intensificação do trabalho, que pode ser exemplificado pela expansão do trabalho de tempo parcial, divisão sexual do trabalho, crescimento do trabalho de emigrantes (ANTUNES, 2000). Na análise deste processo de reestruturação produtiva, Frigotto (1998, p. 15) mostra que

no plano ideológico desloca-se a responsabilidade social para o plano individual. Já não há políticas de empregos e renda dentro de um projeto de desenvolvimento social, mas indivíduos que devem adquirir competências ou habilidades no campo cognitivo, técnico, de gestão e atitudes para se tornarem competitivos e empregáveis.

O sistema capitalista que se expande de forma intensa no século XX, é, nas palavras de Ianni (2002, p. 55), "um modo de produção 
material e espiritual, forma de organizar a vida e o trabalho, ou processo civilizatório, que se expande contínua e reiteradamente pelos quatro cantos do mundo". Ainda segundo esse autor, "os movimentos do capital, tecnologia, força de trabalho, know-how empresarial etc., em escala mundial, transformam as sociedades nacionais em dependências da sociedade global" (2002, p. 43). Nesse sentido, a globalização ocorre nos níveis econômico, político, social e cultural.

Uma das características do processo de globalização, que nos interessa destacar, neste artigo, é a transformação do inglês em língua universal, a língua franca da comunicação, da comercialização, da arte, da classe governante. No âmbito da sociedade global, diante das inúmeras possibilidades de comunicação, onde os espaços são desterritorializados, a língua estrangeira (LE) adquire destaque especial.

Guardadas as diferenças no processo político-econômico-cultural dos países desenvolvidos, a crise da década de 1970 propiciou, no Brasil, uma discussão das questões educacionais. Em decorrência, desenvolveuse um projeto de lei educacional para a implantação da última reforma educacional no século XX no país. As mudanças propostas na legislação regulamentadora das políticas educacionais não se dão em campo neutro nem em circunstâncias aleatórias. È papel dos que se comprometem com o ensino, no país, analisar as determinações que fazem parte da realidade social. Neste sentido, é preciso apreender os nexos constitutivos dessa realidade para se fazer uma reforma intelectual e moral, como diria Gramsci (1991), advinda de uma concepção de mundo que se estabelecesse por meio da vida política.

Verifica-se, então, uma pertinente relação entre políticas educacionais e os processos produtivos (FrigotTo, 1998; MACHADO, 1998; Kuenzer, 1998; GentiLli, 1998). No Brasil, apesar da combinação do modelo de acumulação taylorista-fordista e de acumulação flexível, as medidas adotadas para a reforma procuram atender a uma discussão que acontece em nível mundial, liderada por organismos internacionais Organização das Nações Unidas para a Educação, a Ciência e a Cultura (Unesco) e Fundo das Nações Unidas para a Infância (Unicef).

A realização da Conferência Mundial de Educação para Todos em Jontiem, na Tailândia, em 1990, financiada pela Unesco, Unicef, Programa das Nações Unidas para o Desenvolvimento (Pnud) e pelo Banco Mundial, revelou a necessidade não só de uma ampla reforma 
educacional com vistas ao século XXI, mas também de um novo paradigma educacional como forma de diminuição das desigualdades sociais, da violência e da edificação de um mundo mais solidário.

O relatório para a Unesco da Comissão Internacional sobre a Educação para o Século XXI, mais conhecido como "Relatório Delors", iniciado em março de 1993 e concluído em setembro de 1996, constituise em documento importante para divulgação, sistematização e consolidação em termos de pistas e recomendações dos acordos e compromissos assumidos na Conferência Mundial de Educação para Todos de 1990. Além disso, por meio dele, podemos compreender o que se passa na política de vários países atualmente, incluindo, nesse caso, o Brasil.

O documento produzido pela Comissão faz um diagnóstico do momento por que a civilização passa nesse processo de globalização, mostrando que o ideal de progresso não contribuiu para o aprimoramento das relações humanas. Evidenciam-se as desigualdades sociais existentes e a falta de emprego, que ocorrem inclusive nos países ricos. Apresentase a educação como "trunfo" para a "paz, liberdade e justiça social" (Shiroma; Moraes; Evangelista, 2000, p. 66). Neste sentido, a educação é vista como a possibilidade de dotar a humanidade da capacidade de dominar o seu próprio desenvolvimento. Ela deve, de fato, fazer com que cada um tome o seu destino nas mãos e contribua para o progresso da sociedade na qual está inserido. Ao pensar uma educação que ultrapasse as tensões existentes na sociedade global, o Relatório Delors apresenta quatro princípios básicos para a educação do século XXI: aprender a conhecer, aprender a fazer, aprender a viver juntos e aprender a ser. Aparentemente, poderíamos dizer que houve uma guinada no modelo de educação proposto anteriormente para um projeto educacional não mais assentado na concepção de desenvolvimento econômico, mas no de desenvolvimento humano:

o mundo conheceu, durante o último século, um desenvolvimento econômico sem precedentes. Sem pretender fazer um balanço exaustivo deste período, o que ultrapassa o quadro de seu mandato, a Comissão gostaria de recordar que, em sua perspectiva, estes avanços se devem, antes de mais nada, à capacidade dos seres humanos de dominar e organizar o meio ambiente em função das suas necessidades, isto é, à ciência e à educação, motores principais do progresso econômico. Tendo, porém, consciência de que o modelo 
de crescimento atual depara-se com limites evidentes, devido às desigualdades que induz e aos custos humanos e ecológicos que o comportam, a Comissão julga necessário definir a educação, não apenas na perspectiva dos seus efeitos sobre o crescimento econômico, mas de acordo com uma visão mais larga: a do desenvolvimento humano. (Delors (Org.), 1999, p. 69)

Consideramos, no entanto, que o Relatório Delors naturaliza os efeitos da globalização, apontando somente os pontos positivos do avanço tecnológico e a necessidade de um perfil de cidadão que seja capaz de se adaptar às novas mudanças. Ianni (2002, p. 49) argumenta que "o mesmo processo de globalização da cultura, caminhando junto com o da sociedade, economia e política, ainda que em forma desigual, globaliza também grupos e classes sociais, movimentos sociais e partidos políticos, ideologias e utopias". Nesse sentido,

as desigualdades sociais, econômicas, políticas e culturais estão lançadas em escala mundial. O mesmo processo de globalização com que se desenvolvem a interdependência, a integração e a dinamização das sociedades nacionais, produz desigualdades, tensões e antagonismos. $\mathrm{O}$ mesmo processo de globalização que debilita o Estado-nação, ou redefine as condições de sua soberania, provoca o desenvolvimento de diversidades, desigualdades e contradições, em escala nacional e mundial. (IANNI, 2002, p. 49)

Um ponto enfatizado pelo Relatório Delors é a importância da LE na sociedade global e a ênfase de seu ensino como forma de atender às necessidades de uma sociedade móvel e ao "desenvolvimento de comunicação social" (Delors, 1999, p. 43).

A aprendizagem de LE não é vista apenas com a finalidade de estabelecer comunicação entre os homens, mas também como forma de atender ao mercado mundial do século XXI. As determinações da necessidade do estudo de LE já estão dadas pelo processo de globalização, que encerra algumas características para o aprendizado da língua, como a revolução informática e a organização de um sistema financeiro, com as exigências da economia capitalista mundial determinadas pelos países dominantes.

A insistência do relatório da comissão da Unesco, no que refere ao ensino de línguas, mostra-nos não ser por acaso que a LE, anterior- 
mente relegada a segundo plano no currículo nacional, adquire agora destaque especial, sendo obrigatória nos ensinos fundamental e médio.

\section{A Legislação: LDB n. 9.394/96, PAReCER 15/98 e PCN}

A LDB n. 9.394/96 inclui obrigatoriamente uma LE no currículo do ensino fundamental e médio, além de outra LE, de caráter opcional, no nível médio. Traz, como inovação, a possibilidade de as classes ou turmas serem organizadas "com alunos de séries distintas, com níveis equivalentes de adiantamento na matéria, para o ensino de línguas estrangeiras, artes, ou outros componentes curriculares" (Art. 24, Inciso IV).

Conforme previsto, sua implementação ocorreria por meio da elaboração das diretrizes curriculares. Assim, o Parecer 15/98, de autoria de Guiomar N. de Mello, aprovado em primeiro de junho de 1998, tem como um dos objetivos apreciar e deliberar sobre o documento que "apresenta propostas de regulamentação da base curricular nacional e de organização do Ensino Médio" (BRASIL, Ministério da Educação, Semtec, 1999, p. 59). Esse parecer traça como objetivos para a reforma educacional um processo de formação que desenvolva

a aprendizagem de competências de caráter geral, visando à constituição de pessoas mais aptas a assimilar mudanças, mais autônomas em suas escolhas, mais solidárias, que acolham e respeitem as diferenças, pratiquem a solidariedade e superem a segmentação social. (Idem, ibidem, p. 72).

Com isso, percebemos que o documento busca atender à proposta apresentada no relatório da comissão da Unesco, que almeja uma educação voltada às rápidas mudanças processadas na era digital, um cidadão mais solidário para agir num mundo de conflitos políticoeconômicos e culturais, além de uma educação voltada à preparação do indivíduo para atuar num mundo em que as perspectivas de trabalho se tornam cada vez mais escassas. Ou seja, "as ênfases caminham na direção da valorização do indivíduo, de sua capacidade de iniciativa e de seu espírito de competitividade. Deseja-se formar, em síntese, uma mentalidade econômica, pragmática e realizadora, orientada para a produtividade, para o lucro e para o consumo" (Latapí, apud Moreira, 1996b, p. 132). 
Essa perspectiva de cidadão é solidária e contemporânea do processo de globalização. Ao estabelecer as mediações que configuram o cidadão no mundo, Ianni (2002, p. 110) verifica que

a mercadoria alcançou a cidadania mundial antes que o indivíduo. $\mathrm{O}$ Fundo Monetário Internacional (FMI), o Banco Mundial (BIRD: Banco Internacional de Reconstrução e Desenvolvimento), e o convênio Geral de Tarifas e Comércio (GATT), bem como as empresas transnacionais e agências multilaterais são o gerente da mercadoria nos quatro cantos do mundo. Uma cidadania que está expressa na moeda global, o dólar, e cujo idioma é o inglês, a vulgata de todo o mundo.

O Parecer 15/98, de modo geral, apresenta três objetivos:

1. sistematizar os princípios da LDB;

2. explicar os desdobramentos desses princípios no plano pedagógico e traduzi-los em diretrizes que contribuam para assegurar a formação básica comum nacional;

3. dispor sobre a organização curricular da formação básica nacional e suas relações com a parte diversificada, e a formação para o trabalho (BrAsil, Ministério da Educação, Semtec, 1999, p. 59).

Superar o caráter dual e elitista que o ensino médio vem desenvolvendo ao longo da história por meio das suas funções formativas, a propedêutica e a profissionalizante, é uma das propostas do parecer. Por isso, baseia-se em princípios que possam superar essa dualidade com vistas a uma preparação "básica, ou seja, aquela que deve ser base para a formação de todos e para todos os tipos de trabalho" (BRASIL, Ministério da Educação, Semtec, 1999, p. 70).

Seguindo a orientação do relatório da comissão da Unesco, o Parecer 15/98 da Câmara de Educação Básica do CNE, em analogia aos quatro pilares da educação para o Século XXI - aprender a conhecer, aprender a fazer, aprender a conviver e aprender a ser - define-se pelos seguintes princípios: "estética da sensibilidade, política de igualdade e ética da identidade" (RAmos, 2001).

A estética da sensibilidade volta-se para o estímulo à criatividade, tendo "o espírito inventivo, a curiosidade pelo inusitado, a afetividade, para facilitar a constituição de identidades capazes de suportar a inquietação, conviver com o incerto, o imprevisível e o diferente" (BRASIL, 
Ministério da Educação, Semtec, 1999, p. 75). De acordo com Ramos (2001), a estética da sensibilidade refere-se ao aprender a conhecer e ao aprender a fazer. É na estética da sensibilidade que o parecer traz um ponto bastante controverso no meio educacional, exatamente quando se passa a entendê-lo como entretenimento. Nessa perspectiva, ao se colocar a escola como um espaço também de lazer, ocorre que se captura o homem por inteiro, aprisionando, no tempo do trabalho, o tempo livre:

por essa razão, procura não limitar o lúdico a espaços e tempos exclusivos, mas integrar diversão, alegria e senso de humor a dimensões de vida muitas vezes consideradas afetivamente austeras, como a escola, o trabalho, os deveres, a rotina cotidiana. (Idem, ibidem, p. 76).

Numa outra perspectiva, outras críticas são produzidas, pois a própria expressão estética da sensibilidade chama a atenção se considerarmos a realidade da educação brasileira.

A política da igualdade tem como princípio "o desenvolvimento dos direitos humanos e o exercício dos direitos e deveres da cidadania" (Idem, ibidem, p. 76). Conforme analisa Ramos (2001), este princípio compreende o aprende a conviver. A questão de uma pedagogia que se paute pelo princípio da igualdade tem sido objeto de crítica por parte de educadores nacionais, por considerarem essa visão parcial e ingênua. Conforme afirmação de Kuenzer (2000), isso só é possível numa sociedade cujos cidadãos participem dos bens materiais e culturais em condição de igualdade, fato que não ocorre na sociedade capitalista. Ainda segundo essa autora, a igualdade só pode ser almejada "em uma sociedade na qual os jovens possam exercer o direito à diferença, sem que isso se constitua em desigualdade, de tal modo que as escolhas por determinada trajetória educacional e profissional não seja socialmente determinada pela origem da classe" (Kuenzer, 2000, p. 35-36).

A política da igualdade não propõe a superação da igualdade formal, para uma igualdade de fato, mesmo porque o princípio de igualdade trata de uma prerrogativa constitucional que, na prática, não se efetiva. $\mathrm{Na}$ verdade, o discurso busca legitimar a atual política governamental que entende a política da igualdade como sendo a:

compreensão e respeito ao Estado de Direito e a seus princípios constitutivos abrigados na Constituição: o sistema federativo e o 
regime republicano e democrático. Mas contextualiza a igualdade na sociedade de informação, como valor que é público por ser do interesse de todos, não exclusivamente do Estado, muito menos do governo. (BrasiL, Ministério da Educação, Semtec, 1999, p. 77, grifos do texto).

Ora, a ampliação da igualdade na sociedade de informação soa como uma brincadeira de mau gosto, dadas as necessidades que se fazem presentes no mundo atual. É bem verdade que o discurso difundido é o de que todos os homens são iguais e livres. Em determinadas condições sim, mas, na verdade, à medida que eles não dispõem de condições para serem empreendedores, essa liberdade promulgada não é exercida.

$\mathrm{E}$, finalmente, a ética da identidade tem como princípio básico o reconhecimento da identidade própria e o reconhecimento da identidade do outro. Conforme analisa Ramos (2001), este princípio estaria, na política educacional brasileira, representando o aprender a ser, fundamentado na orientação da Unesco.

A inspiração no relatório Delors consolida-se à medida que o Parecer CEB 15/98 avança, pressupondo um currículo voltado aos princípios axiológicos, a saber:

- fortalecimento dos laços de solidariedade e de tolerância recíproca;

- formação de valores;

- aprimoramento como pessoa humana;

- formação ética;

- exercício da cidadania (Idem, ibidem, p. 104).

Além dos princípios axiológicos, o documento trata ainda de um currículo assentado em princípios pedagógicos. A interdisciplinaridade e a contextualização são duas categorias fundamentais nas atuais tendências contemporâneas de ensino, sendo que ambas estão em sintonia com as novas tendências de ensino de LE. A interdisciplinaridade aparece com destaque nos projetos escolares e, principalmente, na abordagem comunicativa sobre o ensino de línguas estrangeiras. O princípio de contextualização, conforme a relatora, é a possibilidade de o aluno estabelecer uma relação ativa como objeto de conhecimento. Para isso, é preciso prover esse aluno de conteúdos que possam ser relacionados às experiências de vida pessoal, social e cultural. A contextualização é 
"um mero recurso para tornar a aprendizagem significativa ao associála com experiências da vida cotidiana ou com os conhecimentos adquiridos espontaneamente" (Idem, ibidem, p. 94). Para Kuenzer (2000, p. 74), esse critério não é suficiente para superar os currículos sobrecarregados, nem para atender às exigências da nova realidade do mundo do trabalho:

o cotidiano não se explica em si, mas através da história que é feita por homens e mulheres reais, que estabelecem relações entre si e com o mundo através do trabalho em sua dimensão da práxis humana, relações que são de exploração ou de solidariedade, de submissão ou de domínio da riqueza, e, em conseqüência, do conhecimento. Há, portanto, cotidianos contraditórios em permanente processo de embate; o cotidiano da galinha certamente não será o cotidiano da raposa, a não ser quando estabelecem relações enquanto caça e caçador.

O embate de Kuenzer com a proposta da relatora ocorre pelo caráter ideológico do documento, isto é, trata-se de explicitar de que cotidianos se fala e das relações contraditórias neles estabelecidas. Em síntese, considerar a contextualização tomando uma classe como universal, isto é, não fazendo as devidas distinções, significa dar ao ensino uma dimensão ideológica (KUENZER, 2000). Ainda seguindo o raciocínio de Kuenzer, é preciso estabelecer as finalidades de "o que ensinar e como ensinar de forma contextualizada", pois

a educação propõe-se a desenvolver a capacidade de pensar teoricamente a realidade, para o que será preciso abstrair, deduzir leis construindo explicações a partir da identificação de regularidades, ou da apreensão das relações que unificam as partes em uma totalidade e ao mesmo tempo mantém as especificidades. E, o que é mais importante, usar essa capacidade para atuar política e produtivamente de modo a transformar a realidade. Para isto, é preciso ter método, paciência e disciplina, o que nem sempre é interessante ou prazeroso. (KuenZER, 2000, p. 75)

Ainda que as diretrizes curriculares tenham como pressuposto a superação da dualidade histórica existente no ensino médio (propedêutica e profissional), e que o Parecer 15/98 fundamente-se em autores clássicos, na tentativa de mostrar uma aproximação ou sintonia entre suas bandeiras 
de luta e a nova política educacional, o texto do parecer não tem sustentação para isso, pois não faz uma análise das determinações existentes, que expliquem a atual situação da classe que necessita do trabalho. Com isso, o texto torna-se altamente ideológico, transmitindo a idéia de que o sucesso/insucesso do aluno depende única e exclusivamente da sua competência. Soma-se a isso o fato de que é impossível a superação da dualidade entre ensino propedêutico e ensino profissionalizante num mundo socialmente marcado por diferenças materiais, sendo que estas apresentam-se antes mesmo do ingresso do aluno no ambiente escolar.

Se as Diretrizes Curriculares Nacionais fizeram parte de um projeto que visava a aplicação e consolidação da LDB n. 9.394/96, os PCN são a tentativa de um modelo de currículo nacional baseado nas diretrizes. O documento dos PCN busca implementar um currículo nacional flexível, baseado no domínio de competências básicas e vinculado aos diversos contextos de vida de alunos. Apresenta como metas "dar significado ao conhecimento do aluno por meio da contextualização; evitar a compartimentalização mediante a interdisciplinaridade; e incentivar o raciocínio e a capacidade de aprender" (BRASIL, Ministério da Educação, Semtec, 1999, p. 13).

\section{A “NOÇÃo DE COMPETÊNCIA(S)"}

A "noção de competência(s)", ao ser tomada como paradigma nas definições políticas educacionais, passa a ocupar lugar central nas reflexões que tratam dos aspectos educacionais no Brasil e em outros países. A mudança no modelo de formação que se verifica no currículo nacional aponta a necessidade de estudos que busquem compreender em que contexto a "noção de competência(s)" se processa.

No contexto das relações de trabalho, os anos 80 foram férteis na discussão sobre os avanços tecnológicos e a gestão do trabalho. Evidenciada a crise financeira mundial, discutia-se o modelo de acumulação taylorista/fordista e os sinais de seu esgotamento. O modelo em questão, que regeu não só o mundo do trabalho mas também hábitos, valores e conhecimentos, estava em xeque. A explicação que se segue esclarece a mudança de um paradigma que havia se tornado modelo para todas as esferas da vida desde o início do século XX (Harvey, 2000), para a emergência de um novo modelo: 
A profunda recessão de 1973, exacerbada pelo choque do petróleo, evidentemente retirou o mundo capitalista do sufocante torpor da "estagflação" (estagnação da produção de bens e alta da inflação de preços) e pôs em movimento um conjunto de processos que solaparam o compromisso fordista. Em conseqüência, as décadas de 70 e 80 foram um conturbado período de reestruturação econômica e de reajustamento social e político. No espaço social criado por todas essas oscilações e incertezas, uma série de novas experiências nos domínios da organização industrial e da vida social e política começou a tomar forma. Essas experiências podem representar os primeiros ímpetos da passagem para um regime de acumulação inteiramente novo, associado com um sistema de regulamentação política e social bem distinta. (HARVEY, 2000. p. 140)

Era preciso, então, um novo conceito de qualificação que atendesse ao modelo de produção flexível. O perfil do novo trabalhador deveria ser o de um indivíduo polivalente, competitivo, adaptativo, capaz de solucionar os problemas que porventura surgissem (HIRATA, 1994; MACHADO, 1994; SHIROMA e CAMPOS, 1997). Ao analisar o novo paradigma, Kuenzer (2000) assinala que o discurso, referente ao novo tipo de trabalhador para todos os setores da economia, requer o destaque para algumas capacidades intelectuais, dentre as quais destacam-se: comunicar-se adequadamente na língua portuguesa e em LE; autonomia intelectual para a resolução de problemas práticos; autonomia moral por meio da capacidade de enfrentar as novas situações que demandam posicionamento ético e, ainda, capacidade de comprometer-se como trabalho.

O modelo de acumulação flexível coloca em cena o "modelo de competência" que "surge como alternativa, no plano empresarial, para orientar a formação de recursos humanos compatível com a organização do trabalho que lhe convém" (FERRETI, 1997, p. 229). Daí, a afirmação de Hirata (1994, p. 132) de que a competência é "uma noção oriunda do discurso empresarial nos últimos dez anos e retomada por economistas na França".

No Brasil, a disseminação da formação assentada nos princípios das competências ocorre por meio dos documentos do Ministério da Educação na segunda metade da década de 1990, tais como Diretrizes Curriculares Nacionais e Parâmetros Curriculares Nacionais.

Existe uma vasta literatura sobre o tema "competência(s)" na área da educação, embora o mesmo não se verifique no campo da lingüística 
aplicada. As investigações desenvolvidas, na educação, se dão sob diversas óticas, ressaltando-se três tendências que vêm sendo amplamente discutidas por teóricos nacionais e estrangeiros. Uma que considera a "noção de competência(s)" uma ressignificação da pedagogia por objetivos (PACHECO, 2002). Outra que considera a "noção de competência(s)" diferente da pedagogia por objetivos, portanto, um novo significado ao conceito de competência, particularmente devido ao advento da psicologia e às mudanças no mundo do trabalho (HIRATA, 1994; KUENZER, 2002). Finalmente, uma terceira posição que diz ser a "noção de competência(s)" algo novo, não tendo relação com as teorias já produzidas (Perrenoud, 1999), e é esta última que passaremos a discutir.

Perrenoud (1999), sociólogo e professor na Faculdade de Psicologia e Ciências da Educação da Universidade de Genebra, se insere entre aqueles que difundem a pedagogia por competências. Disposto a defender uma educação para agir em uma sociedade em constante mudança e que adquire complexidade, Perrenoud (1999) postula uma pedagogia por competências que tem o conhecimento gerado a partir da ação. Utilizando-se de uma retórica que ilustra os limites de uma educação conservadora e a possibilidade de mudança por meio da pedagogia por competências, avalia que, no campo educacional, a resistência em adotar essa pedagogia ocorre por uma ação de educadores altamente conservadores, que fundamentam sua prática docente ainda na pedagogia por objetivos. Critica aqueles que explicam o surgimento da noção de competências no processo educacional a partir das mudanças ocorridas no modelo de acumulação flexível e nas formações profissionais. Para ele, a noção de competências no meio educacional ocorre pelo fato de outros atores, que não os das universidades, estarem defendendo o utilitarismo. Segue em defesa dos primeiros, posto que advogam a favor de "uma escolaridade que permita a apreensão da realidade" (PERRENOUD, 1999, p. 14).

Perrenoud (1999) reconhece que as habilidades fazem parte da competência, contudo, elas não requerem reflexão. Assim, entende que

a habilidade é uma "inteligência capitalizada", uma seqüência de modos operatórios, de analogias, de intuições, de induções, de deduções, de transposições dominadas, de funcionamentos heurísticos rotinizados, que se tornaram esquemas mentais de alto nível ou tramas que ganham tempo e "inserem" a decisão. 
Por outro lado, "construir uma competência significa aprender a identificar e a encontrar os conhecimentos pertinentes" (PERRENOUd, 1999, p. 22). Conforme afirmação do autor, os conhecimentos são "representações da realidade, que construímos e armazenamos ao sabor de nossa experiência e de nossa formação" (1999, p. 7).

Essa generalização do termo "conhecimento" é criticada por Kuenzer (2002), uma vez que se refere a um conhecimento fundamentado na experiência. A autora aponta como um dos principais problemas na teoria de Perrenoud o fato de ele não tratar adequadamente "as categorias de análise que permitem compreender as relações entre trabalho e educação" (2002, p. 5).De fato, Perrenoud se atém ao mundo da escola. Ao propor a competência como "uma capacidade de agir eficazmente em determinado tipo de situação, apoiada em conhecimentos, mas sem limitar-se a eles" (PerRENoud, 1999, p. 7), o autor não revela a que tipo de conhecimento está se referindo. Kuenzer (2002, p. 6), com base em estudos empíricos, revela que "os trabalhadores mobilizam distintos tipos de conhecimento, que não são equivalentes". As situações vivenciadas por trabalhadores indicam que nem sempre o que detém mais conhecimento teórico é o que age com mais eficiência em situações de risco, ou seja, "conhecimento e competências são processos que se articulam mas que não se identificam" (KUENZER, 2002).

Defendendo uma postura dialética em relação ao conceito de práxis no que concerne à teoria e à prática, Kuenzer (2002) expressa a necessidade de se compreender a prática como uma ação transformadora tanto das relações sociais quanto das relações produtivas. Daí o conceito de conhecimento como apenas reprodutor da realidade ser recusado pela autora. Os princípios devem, no seu entendimento, se respaldar na possibilidade de transformação dessa realidade com base na atividade crítico-prática.

Ainda no campo da pedagogia das competências, Perrenoud (2002) afirma que a "competência se manifesta na ação", é altamente criativa e situa-se "além dos conhecimentos" (1999, p. 31), ao passo que "possuir capacidades não significa ser competente. Pode-se conhecer técnicas ou regras de gestão e não saber aplicá-las no momento oportuno" (2002, p. 1). Para o autor, as competências podem ser observadas e avaliadas. Elas são fundamentais na formação do aluno, pois oferecem a possibilidade de "responder a uma demanda social dirigida para a adaptação ao mercado e às mudanças e também podem fornecer os meios para apreen- 
der a realidade e não ficar indefeso nas relações sociais" (PERRENOUd, 1999, p. 32). O autor não tem dúvidas de que a pedagogia das competências é o passaporte para a superação da atual situação do ensino básico.

A pedagogia das competências propõe uma série de mudanças no interior da escola, começando pela mudança curricular (sugerindo uma nova organização e mudança nos conteúdos disciplinares), passando pela formação do professor, pela contextualização até a aprendizagem significativa. Enfim, carrega em seus postulados uma maneira diferente de ver a educação num sentido mais pragmático, mais utilitarista, menos clássico e mais aplicado.

Entendendo que a escola precisa preparar o aluno para atuar em sociedade de forma a acompanhar as mudanças ocorridas no mundo, as idéias difundidas por Perrenoud (1999) encontram-se consolidada no Parecer CEB 15/98 sobre as Diretrizes Curriculares para o Ensino Médio. Kuenzer (2002, p. 16-17), opondo-se a essas idéias, diz que o dever da escola é desenvolver as "capacidades cognitivas, afetivas e psicomotoras relativas ao trabalho intelectual", articuladas ao mundo do trabalho e às relações sociais, ao passo que as competências devem ser desenvolvidas na prática social e produtiva, pois, ainda que mobilizem conhecimentos, com eles não se confundem.

Com efeito, o deslocamento de uma abordagem gerada no espaço da fábrica há de trazer conseqüências e apresentar problemas incontornáveis para a pedagogia. Conforme apontado por Kuenzer (2002, p. 15), no que se refere ao conceito de práxis,

os processos educativos escolares, sejam de educação geral, profissional ou ambas, se configuram como espaços de articulação com o conhecimento socialmente produzido, enquanto produtos, e como espaços de apreensão das categorias de produção deste conhecimento, enquanto processos metodológicos. São, por excelência, espaços da produção teórica, do trabalho intelectual, sempre que possível articulado à práxis, mas sempre incapaz de reproduzi-la em seu movimento e em sua complexidade.

Conforme afirmado anteriormente, Kuenzer (2002, p. 16) entende que não se pode confundir o espaço da escola com o espaço em que se desenvolve a prática social e produtiva, pois

proclamando a escola como responsável pelo desenvolvimento de competências, resulta em mais uma forma, sutil, mas extremamente 
perversa, de exclusão dos que vivem do trabalho, uma vez que os filhos da burguesia desenvolvem suas capacidades apesar da escola, que para muitos passa a ser apenas uma instituição certificadora; para os trabalhadores, a escola se constitui no único espaço de relação intencional e sistematizadora do conhecimento.

Desconsideramos que a pedagogia das competências seja algo novo, que não tenha relação com outras teorias ou que não esteja relacionada às competências que tiveram origem no mundo do trabalho, o que vai de encontro ao pensamento de Perrenoud (1999).

Entendemos que essa proposta empobrece de maneira contundente o processo educacional nos seus aspectos teóricos que tratam das categorias "conteúdo", "professor", "competências e habilidades" e, ainda, "aluno".

Lopes (2001) avalia que o conceito de competências subjaz às diretrizes curriculares nacionais para o ensino médio e se associa tanto às dimensões cognitivas advindas de contextos que fogem ao domínio da educação, como, por exemplo, a teoria das competências do campo das ciências sociais, quanto aos enfoques comportamentalistas provenientes do conceito de competências da teoria curricular. Se as competências são entendidas como comportamentos mensuráveis e cientificamente controláveis, elas não deixam de se enquadrar na perspectiva comportamentalista, haja vista a possibilidade de as "atividades de ensino serem decompostas em supostos elementos componentes (as habilidades) que permitem a elaboração de indicadores de desempenho para avaliação" (LOPES, 2001, p. 4).

Conforme atesta Kuenzer (2002, p. 2), o conceito de competência no atual contexto do mundo do trabalho é influenciado pelo toyotismo, uma variação do modelo de acumulação flexível, e "passa a supor o domínio de conhecimento científico-tecnológico e sócio-histórico em face da complexificação dos processos de trabalho, com impactos nas formas de vida social". Daí a defesa de Kuenzer de "um novo significado ao conceito de competência a partir das mudanças ocorridas no mundo do trabalho, ao se pretender a inclusão: o domínio do conhecimento articulado ao desenvolvimento das capacidades cognitivas complexas, ou seja, das competências relativas ao domínio teórico" (2002, p. 2).

No nosso entendimento, a "noção de competência(s)" é muito limitada para se pensar a formação humana. A escola, para ser demo- 
crática, precisa ir além da preparação para o trabalho, é preciso formar para a humanização. Na perspectiva do Parecer 15/98, a escola reduz-se ao mundo do trabalho. Não devemos confundir formação ampla, que prepara também para o trabalho, com formação para o desempenho das atividades produtivas. É possível dizer que precisamos pensar a educação no contexto global, levando em consideração a concepção de trabalho, de autonomia e de cidadania de uma forma que conduza o cidadão à universalidade e à liberdade plena, buscando ver a educação como uma prática social que compreenda o trabalho não como "uma forma particular mas como a essência ontológica da vida humana na qual derivam todas as outras formas de atividade" (Resende, 1992, p. 57).

Acreditamos ser necessário o entendimento do que as políticas educativas propõem, porque não concordamos com uma formação assentada nos princípios da economia do mercado, que adquirem na sociedade capitalista o papel de protagonista da história.

\section{ParÂmetros Curriculares Nacionais de Língua Estrangeira Para O ENSINO MÉDIO}

O documento Parâmetros Curriculares Nacionais (BrasIL, Ministério da Educação, Semtec, 1999) é, nas palavras de Lopes (2002, p. 390), "a carta de intenções governamentais para o nível médio", em que se encontram presentes as idéias da reforma, a orientação pedagógica que desenvolve a produção do conhecimento e a corrente teórica na qual ela se insere.

Ancorada no desenvolvimento das competências desejáveis no plano do desenvolvimento humano e na aproximação delas às competências exigidas para o exercício da cidadania e da atividade produtiva, a nova proposta educacional para o ensino médio afirma que sua orientação propõe a educação como elemento de desenvolvimento social. Com base nisso, propõe como orientação das disciplinas que constituem o currículo o desenvolvimento de competências e habilidades, interdisciplinaridade, contextualização e currículo por competências, que são os princípios balizadores do documento.

Baseados na revolução tecnológica e na globalização, os parâmetros curriculares nacionais (PCN) assumem que as línguas estrangeiras, a partir dessa reforma, têm como função a comunicação. A comunicação não se manifesta apenas na expressão oral, mas se apóiam 
também nos gestos que dizem muito sobre a forma de pensar das pessoas, assim as tradições e a cultura de um povo esclarecem muito sobre aspectos da sua forma de ver o mundo e de aproximar-se dele" (BRASIL, Ministério da Educação, Semtec, 1999, p. 148). Com isso, abre-se a possibilidade de relacionar o ensino de LE às demais disciplinas que integram a área de Linguagens, Códigos e suas Tecnologias.

Os PCN tratam do caráter formativo que a disciplina LE deve ter. Ressaltamos que o lingüista Daniel N. Martins da Costa (1987) já falava isso na década de 1980, enquanto também Delors (1999, p. 135), no relatório para a Unesco da Comissão Internacional sobre a Educação para o século XXI, faz a seguinte afirmação:

(línguas, ciência, cultura geral) deveriam ser enriquecidos e atualizados de modo a refletir a mundialização crescente de fenômenos, a necessidade de uma compreensão intercultural e a utilização da ciência a serviço de um desenvolvimento humano sustentável. Por outras palavras, é preciso preocupar-se mais com a qualidade e preparação para a vida, num mundo em rápida transformação, freqüentemente submetido ao império da tecnologia.

Os PCN elencam alguns problemas enfrentados pela língua estrangeira: o professor não é devidamente qualificado; o número de horas-aula é reduzido; o material não é de qualidade; e, por fim, a hegemonia do ensino de inglês. Com base nestas evidências, tem-se como desdobramento: aulas monótonas e repetitivas, baseadas no ensino de regras gramaticais; pouca valorização dos conteúdos relevantes à formação dos aprendizes; falta de interesse do professor na formação lingüística de outras línguas estrangeiras. Daí a necessidade de as línguas estrangeiras assumirem a sua função de estabelecer comunicação entre os homens, reverem suas metodologias, trazendo para o centro do processo a figura do aluno, revitalizando o papel do professor que recebe como designação os termos "facilitador", "orientador", "mediador", "guia", e, ainda propondo um conteúdo centrado nas necessidades dos alunos. Além disso, o documento afirma que, para haver mudança, é preciso que a concepção de ensino e, no caso, a concepção de ensino de LE, seja revista.

Nesse sentido, o documento assinala que os seguintes pontos merecem atenção: o monopólio lingüístico da língua inglesa nas escolas públicas e a criação de centros de estudos de línguas estrangeiras. 
Conforme os PCN, apesar de a língua inglesa desempenhar importante papel no mundo moderno, ela não deve ser a única possibilidade a ser oferecida ao aluno, pois, "verificou-se, nos últimos anos, um crescente interesse pelo estudo do castelhano" (BrasiL, Ministério da Educação, Semtec, 1999, p. 149). Considerando a importância das duas línguas no mundo globalizado, ao escolher a(s) línguas(s) estrangeira(s) que a escola oferecerá, deve-se levar em conta as características sociais, culturais e históricas da região onde o estudo vai ocorrer. Essa possibilidade está dada pela própria LDB n. 9.394/96, que inclui uma segunda língua opcional no ensino médio.

Os PCN tratam ainda da importante experiência de oferta de línguas estrangeiras e dos objetivos de sua aprendizagem que acontece nos Centros de Estudos de Línguas Estrangeiras existentes nas regiões Sul e Sudeste do país, São Paulo e Paraná.

Segundo os PCN, é no domínio das seguintes competências que se alcança a competência comunicativa:

- Saber distinguir entre as variantes lingüísticas.

- Registro adequado à situação na qual se processa a comunicação.

- Escolher o vocábulo que melhor reflita a idéia que pretenda comunicar.

- Compreender de que forma determinada expressão pode ser interpretada em razão de aspectos sociais e/ou culturais.

- Compreender em que medida os enunciados refletem a forma de ser, pensar, agir e sentir de quem os produz.

- Utilizar os mecanismos de coerência e coesão na produção em Língua Estrangeira (oral e/ou escrita). Todos os textos referentes à produção e à recepção em qualquer idioma regem-se por princípios gerais de coerência e coesão e, por isso, somos capazes de entender e de sermos entendidos.

- Utilizar as estratégias verbais e não-verbais para compensar falhas na comunicação (como o fato de não ser capaz de recordar momentaneamente uma forma gramatical ou lexical), para favorecer a efetiva comunicação e alcançar o efeito pretendido (falar mais lentamente, ou enfatizando certas palavras, de maneira proposital, para obter determinados efeitos retóricos, por exemplo) (BRASIL, Ministério da Educação, Semtec, 1999, p. 150). 
As competências anteriormente mencionadas evidenciam que, além da competência gramatical, o aluno deve ter outras competências, pois se trata mais do que saber compor frases corretas - é preciso saber adequá-las ao contexto. Para isso, o aluno precisa da competência gramatical ou lingüística, competência sociolingüística, competência discursiva e, ainda, da competência estratégica. De acordo com Canale (1983), a competência gramatical diz respeito ao domínio do código lingüístico, incluindo vocabulário, pronúncia, ortografia. A competência sociolingüística refere-se ao papel dos falantes em contextos situacionais e à escolha de registro e estilo. A competência discursiva envolve a habilidade de combinar idéias para alcançar coesão na forma e coerência no pensamento. E a competência estratégica considera que não há falantes/ ouvintes ideais, sendo necessário, portanto, a utilização de estratégias para compensar determinadas lacunas na comunicação.

Atendendo aos princípios pedagógicos propostos pelas Diretrizes Curriculares Nacionais, o documento sinaliza para um trabalho interdisciplinar. Propõem-se alguns comentários e exemplos de como se pode utilizar do conteúdo a ser ensinado, relacionando-o com outras disciplinas.

Por fim, apresenta-se um quadro, dividido em três partes, que tratam das seguintes categorias: representação e comunicação; investigação e compreensão; e contextualização sociocultural.

Trata-se, na verdade, de uma síntese do exposto ao longo do texto no que se refere à aquisição de competências; acrescentou-se, contudo, o termo "habilidades".

Os princípios curriculares subjacentes à proposta de ensino de LE podem ser resumidos nos princípios pedagógicos propostos pelas Diretrizes Curriculares Nacionais: interdisciplinaridade, contextualização e, ainda, conhecimento da cultura da língua-alvo. Por contextualização, no documento, entende-se que os conteúdos a serem trabalhados devem se relacionar de alguma forma com o conhecimento prévio do aluno e com a cotidianidade do aprendiz.

As orientações apresentadas pelos PCN derivam-se da ampla literatura sobre o ensino de LE que tem, ao longo dos últimos anos, centralizado o seu foco na figura do aluno, facilitado a assimilação do conteúdo, criticado o conteúdo clássico, relegado o papel do professor a segundo plano, desconsiderado a produção de conhecimento histori- 
camente construída e delegado às escolas o papel de preparar o aluno para atender às exigências mais imediatas.

\section{CONSIDERAÇÕES FINAIS}

Este estudo indica que a abordagem defendida pelos PCN fundamenta-se na discussão teórica realizada pelos lingüistas brasileiros e internacionais (Costa, 1987; Consolo, 1990; Almeida Filho, 1993; Vieira Abrahão, 1996; SAVIGNON, 1983; Widdowson, 1990; Moita Lopes, 1996; NunAN, 1999). O documento referente ao ensino médio fundamenta-se nas tendências contemporâneas de ensino de LE, cujos pressupostos são a integração da competência lingüística (o que é possível no âmbito formal), psicolingüístico (o que é possível em termos de processamento da informação humana), sociocultural (o significado social ou valor dado à fala) e probabilístico (o que realmente ocorre) (Neves, 1996, p. 72).

$\mathrm{Na}$ disciplina de língua inglesa, é possível verificar as mudanças ocorridas na concepção de aprendizado de LE. Essas mudanças vêm na sugestão de uma nova metodologia, no papel do professor, na concepção de conhecimento, na capacidade e habilidade, no papel do aluno, na orientação para o trabalho e nos conteúdos.

Se, conforme LDB n. 9.394/96, uma das finalidades do ensino médio é a consolidação e o aprofundamento dos conhecimentos adquiridos no ensino fundamental, possibilitando o prosseguimento de estudos (Brasil, Ministério da Educação, Semtec, 1999, p. 31), há de se inferir que o ensino médio dará continuidade ao desenvolvimento da leitura, conforme proposta dos PCN para o ensino fundamental. Há de se considerar que existe uma reforma educacional no país, em andamento, e que os princípios que a orientam não se dão em campo neutro. Seria oportuno que os proponentes da reforma dessem esclarecimentos sobre a formulação dos PCN para o ensino fundamental e médio produzidos por dois grupos distintos. Tal fato resultou no uso de concepções teóricas pertencentes a correntes teóricas distintas.

As políticas adotadas na reforma para o ensino de LE, portanto, pautam-se por propostas de mudanças no processo educacional dos países em desenvolvimento, em nível mundial, e que sistematizam ao longo da última década; contudo, a proposta de desenvolver o currículo de LE pautado pelo domínio de competências, que leve o aluno a atingir a 
competência comunicativa, não provoca modificações no atual processo de ensino de LE quanto aos problemas elencados pelos PCN para o ensino médio, tais como: baixa qualificação dos recursos humanos, número reduzido de horas-aula, recursos didáticos escassos. Neste sentido, não há uma relação direta entre os problemas apontados pelo documento e a sugestão apresentada.

A "noção de competência(s)" veiculada pela legislação educacional, no Brasil, propõe que o currículo seja flexível, pois a sociedade encontra-se num contexto em que as informações e a produção tecnológica são processadas de maneira muito rápida, demandando o perfil de um novo cidadão, polivalente, adaptativo e competitivo. Assim, fica evidenciada a concepção de que educar é promover o ajustamento do aprendiz a uma determinada realidade.

No desenvolvimento de nosso estudo, deparamos-nos com algumas dificuldades como a escassa literatura referente à nova proposta de ensino de línguas para o nível médio e a inconsistência conceitual da categoria componentes da pedagogia das competências. Por isso, avaliamos que o tema balizador da reforma é ainda muito recente e merece mais discussões não só como forma de entendimento por parte de quem atua no meio educacional, mas também como meio de reavaliar o que está sendo proposto para a formação do aprendiz. Conhecer mais verticalizadamente a discussão que vem sendo realizada sobre a "noção de competência(s)" é um movimento necessário para pensarmos um ensino de inglês que seja, de fato, universal e que atinja todas as classes, pois o domínio da língua inglesa é uma condição necessária no contexto da globalização.

Se a proposta da reforma para o ensino médio respalda-se pela igualdade de oportunidades, vale perguntar: como tornar possível a prerrogativa igualdade de oportunidades num país onde se delineia um quadro dominado pela apropriação diferencial de riqueza material? A mudança de paradigma do modelo audiolingual para um ensino que tenha como finalidade a aquisição da competência comunicativa garante ao aprendiz a sua qualificação?

\section{ABSTRACT}

This paper is part of the thesis "The teaching of English at the high school level in the Brazilian educational reform: the notion of communicative competence in the text-book." and it attempts to understand the relation of the Brazilian educational reform regarding the teaching of English supported by the economical 
and political references that were developed in the 1990 decade, under the competences bases. It shows the main principles of English high school teaching reform based on the documents formulated by Brazilian government and it concludes that there is a relation between the theoretical papers concerning to second language acquisition, economical and educational politics.

Keywords: brazilian educational reform; national curriculum parameters; competences; foreign language.

\section{REFERÊNCIAS}

ALMEIDA FILHO, J. C. Dimensões cComunicativas no ensino de línguas. Campinas, SP: Pontes, 1993.

ANTUNES, R. Os sentidos do trabalho. 3. ed. São Paulo: Boitempo, 2000.

BRASIL. LDB. Congresso Nacional. Lei n. 9.394, de 20 de dezembro de 1996. Estabelece as diretrizes e bases da educação nacional. In: BRASIL. Ministério da Educação. Secretaria da Educação Média e Tecnológica. Parâmetros curriculares nacionais: ensino médio. Brasília: Ministério da Educação, 1999, p. 39-57.

BRASIL/CNE/CEB. Resolução CEB n. 03, de 26 de junho de 1998. Institui as DCN para o Ensino Médio. In: BRASIL. Ministério da Educação. Secretaria da Educação Média e Tecnológica. Parâmetros curriculares nacionais: ensino médio. Brasília: Ministério da Educação, 1999, p. 112-118.

BRASIL. Ministério da Educação e Cultura. Conselho Nacional de Educação. Parecer CEB n. 15/98. Relatora: Guiomar Namo de Mello. Diretrizes Curriculares Nacionais para o Ensino Médio. In: BRASIL. Ministério da Educação. Secretaria da Educação Média e Tecnológica. Parâmetros curriculares nacionais: ensino médio. Brasília: Ministério da Educação, 1999, p. 59-112.

BRASIL. Ministério da Educação. Secretaria da Educação Média e Tecnológica. Parâmetros curriculares nacionais: ensino médio. Brasília: Ministério da Educação, 1999.

CANALE, M. From Communicative Competence to Communicative Language Pedagogy. In: RICHARDS, J. C.; SCHIMIDT, R (Org.) Language and communication. London: Longman, 1983. p. 1-47.

CONSOLO, D. A. O livro didático como insumo na aula de língua estrangeira (inglês) na escola pública. 1990. Dissertação. (Mestrado em Lingüística Aplicada) - Instituto de Estudos da Linguagem da Universidade Estadual de Campinas, Campinas, SP.

COSTA, D. N. M. da. Por que ensinar lingua estrangeira na escola de $1^{\circ}$ grau. São Paulo: EPU, EDUC, 1987. 
DELORS, J. (org.). Educação: um tesouro a descobrir. 2. ed. São Paulo: Cortez, 1999.

DELUIZ, N. A globalização econômica e os desafios à formação profissional. Disponível em: <http:// www. senac.br>. Acesso em: 04 jan. 2002.

DUARTE, M. S. O ensino de inglês para o nível médio na reforma educacional brasileira: a noção de competência comunicativa no livro-texto. 2003. Dissertação. (Mestrado em Educação Brasileira) - Faculdade de Educação da Universidade Federal de Goiás, Goiânia.

FRIGOTTO, G. Educação, crise do trabalho assalariado e do desenvolvimento: teorias em conflito. In: FRIGOTTO, G. (Org.). Educação e crise do trabalho: perspectivas de final de século. Petrópolis, RJ: Vozes, 1998. p. 25-54.

GENTILI, P. Educar para o desemprego: a desintegração da promessa integradora. In: FRIGOTTO, G. Educação e crise do trabalho: Perspectivas de Final de Século. Petrópolis, RJ: Vozes, 1998. p. 76-91.

GRAMSCI, A. Maquiavel, a política e o estado moderno. 8. ed. Rio de Janeiro: Editora Civilização Brasileira, 1991.

HARVEY, D. Condição pós-moderna. Uma pesquisa sobre as origens da mudança cultural. 9. ed. São Paulo: Edições Loyola, 2000.

HIRATA, H. Da polarização das qualificações no modelo de competências. In: FERRETI, C. J. et al. (Org.). Tecnologias, trabalho e educação. Um debate multidisciplinar. Petrópolis: Vozes, 1994. p. 128-142.

IANNI, O. A sociedade global. 10. ed. Rio de Janeiro: Civilização Brasileira, 2002 .

KUENZER, A. Z. Desafios teóricos-metodológicos da relação trabalho-educação e o papel da escola. In: FRIGOTTO, G. (Org.) Educação e crise do trabalho: perspectivas de final de século. 3. ed. Petrópolis: Vozes, 1998. p. 55-75.

A difícil superação da dualidade estrutural em uma sociedade dividida e desigual. In: KUENZER, A. Z. (Org.). Ensino médio. Construindo uma proposta para os que vivem do trabalho. São Paulo: Cortez, 2000. p. 35-38.

A concepção de ensino médio e profissional no Brasil: a história da construção de uma proposta dual. In: KUENZER, A. Z. (Org.). Ensino médio. Construindo uma proposta para os que vivem do trabalho. São Paulo: Cortez, 2000. p. 27-38.

(Org.). A função social do ensino médio. Construindo uma proposta para os que vivem do trabalho. In: KUENZER, A. Z. A (Org.). Ensino médio. Construindo uma proposta para os que vivem do trabalho. São Paulo: Cortez, 2000. p. 42-90. 
. Conhecimento e competências no trabalho e na escola. Disponível em: $<$ http://anped. org.br>. Acesso em: 22 out. 2002.

LOPES, A. C. Competências na organização curricular da reforma do ensino médio. Boletim Técnico do Senac, Rio de Janeiro, v. 27, n. 3. 2001. p. 1-20.

Os parâmetros curriculares nacionais para o ensino médio e a submissão ao mundo produtivo: $\mathrm{O}$ caso do conceito de contextualização. Educação \& Sociedade. 80 v. 23, 2002. p. 389-403.

MACHADO, L. R. S. A educação e os desafios das novas tecnologias. In: FERRETI, C. J. et al. (Orgs.). Tecnologias, trabalho e educação. Um debate multidisciplinar. Petrópolis: Vozes, 1994. p. 169-188.

. O "modelo de competências" e a regulamentação da base curricular nacional e de organização do ensino médio. Trabalho \& Educação. Belo Horizonte, n. 4. 1998. p. 80-95.

MOITA LOPES, L. P. Oficina de lingüiśtica aplicada. Campinas, SP: Mercado das Letras, 1996.

MOREIRA, A. F. B. Os parâmetros curriculares nacionais: críticas e alternativas. In: SILVA, T.T. da; GENTILI, P. (Orgs.). Escola S.A. Brasília, 1996b. p. 128149.

NEVES, M. de S. Os mitos de abordagens tradicionais e estruturas ainda interferem na prática em sala de aula. In: PAIVA, V. L. M. de O. e. Ensino de língua inglesa. Reflexões e experiências. Campinas, SP: Pontes, 1996. p. 6980.

NUNAN, D. Second language teaching \& learning. Boston, Massachussets: Heinle \& Heinle Publishers, 1999.

PACHECO, J. A. Competências curriculares: as práticas ocultas nos discursos das reformas. Disponível em: <http://anped.org.br>. Acesso em: 22 out. 2002.

PERRENOUD, P. Construir as competências desde a escola. Porto Alegre: Artes Médicas Sul, 1999.

. Uma competência mobiliza saberes. Disponível em: $<\mathrm{http}: / /$ www.sinprors. org.br>. Acesso em: 28 nov. 2002.

RAMOS, M. N. A pedagogia das competências: autonomia ou adaptação? São Paulo: Cortez, 2001.

RESENDE, A. C. A. Fetichismo e subjetividade. 1992. Tese (Doutorado em Ciências Sociais) - Pontifícia Universidade de São Paulo, São Paulo.

SAVIGNON, S. J. Communicative competence: theory and classroom practice. reading, Massachussets: Addison-Wesley Publishing Company, Inc., 1983. 
SHIROMA, E. O.; CAMPOS, R. F. Qualificação e reestruturação produtiva: um balanço das pesquisas em educação. Educação e Sociedade, v. 18, n. 61, dez. 1997. Campinas, p. 1-19.

SHIROMA, E. O.; MORAES, M. C. M.; EVANGELISTA, O. Os arautos da reforma e a consolidação do consenso: anos de 1990. In: . Política educacional. Rio de Janeiro: DP\&A, 2000. p. 53-120.

VIEIRA ABRAHÃO, M. H. Conflitos e incertezas do professor de língua estrangeira na renovação de sua prática de sala de aula. 1996. Tese. (Doutorado em Lingüística Aplicada) - Instituto de Estudos da Linguagem, Universidade Estadual de Campinas, Campinas.

WIDDOWSON, H. G. Teaching language as communication. Hong Kong: Oxford University Press, 1990. 
